\title{
$\mathrm{PH} 9 \mathbf{1}_{\text {panorama }}$
}

\section{Interpretación del patrimonio. Una guía bibliográfica actualizada}

\begin{abstract}
Cuando en los años 80 del siglo pasado la interpretación del patrimonio llegó a España, no existía ninguna publicación en castellano sobre el tema y, en todo caso, el acceso a las obras más trascendentes en la materia era una tarea casi imposible. La disciplina ha evolucionando, se han desarrollado de nuevas especialidades y durante estos años el Seminario Permanente de Interpretación del Patrimonio Natural y Cultural $^{1}$ ha realizado una labor continuada de búsqueda y referencia de información hasta elaborar una guía bibliográfica actualizada que está disponible para descarga gratuita.
\end{abstract}

Francisco J. "Nutri" Guerra Rosado | Servicios de Educación y Estudios Ambientales

URL de la contribución <www.iaph.es/revistaph/index.php/revistaph/article/view/3908>

La interpretación del patrimonio (entonces interpretación ambiental) llegó a España en los años 80 del siglo pasado de la mano de profesionales que habían visitado EE.UU. o se habían formado en América Latina. Entonces las publicaciones sobre la materia en castellano no existían.

Durante esos años, en los que la disciplina ha evolucionado, justificando su razón de ser gracias a la investigación y el desarrollo de nuevas especialidades, y encontrando nuevos nichos que hasta entonces le habían estado vedados, como era el caso del patrimonio cultural. Han sido sobre todo los centros de información y documentación ambiental, constituidos en el año 2004 en red (RECIDA), quienes se han ocupado de ampliar sus fondos tanto con las primeras obras como con aquellas que, en diferentes formatos, iban apareciendo poco a poco en el mercado. Su esfuerzo en la recopilación y divulgación de la interpretación como disciplina de comunicación y puesta en valor del patrimonio merece sin duda el mayor de los agradecimientos.

En este contexto, en 2016, transcurridos diez años desde el nacimiento del Seminario Permanente de Interpretación del Patrimonio Natural y Cultural y a propuesta del centro de documentación del CENEAM (Centro Nacional de Educación Ambiental), este grupo de trabajo consideró la oportunidad de elaborar una guía bibliográfica actualizada que aglutinase la documentación más relevante en la materia. Además de aportar una información de especial interés tanto para los profesionales, como para quienes empiezan a tener contacto con la disciplina: la localización de los centros RECIDA donde se pueden localizar y solicitar en préstamo.

La labor de búsqueda y referencia de la información fue llevada a cabo por personal técnico de algunos de los centros que forman parte de la red, siendo la selección final fruto del trabajo de algunos miembros del seminario.

La guía, disponible para descarga pública, incluye libros, revistas, artículos, comunicaciones a congresos (facilitando el acceso al texto completo en algunos documentos), así como enlaces de interés en la red, y contempla todo un abanico de temáticas (aspectos teóricos, comunicación, turismo e interpretación, diseño de medios interpretativos, etc.). Se destacan, además, las diez publicaciones que, según algunos de los colaboradores del seminario, pueden considerarse "imprescindibles" en materia de interpretación del patrimonio.

\section{NOTA}

1. El Seminario Permanente de Interpretación del Patrimonio Natural y Cultural (SEMIP) es un grupo de 25 profesionales patrocinado por el Centro Nacional de Educación Ambiental (CENEAM)-Ministerio de Agricultura y Pesca, Alimentación y Medio Ambiente. 